\title{
The Association Between Circulating Inflammatory Markers and Metabolic Syndrome in Korean Rural Adults
}

\author{
So Yeon Ryu, Ki Soon Kim, Jong Park, Myeng Guen Kang, Mi Ah Han
}

Department of Preventive Medicine, Chosun University Medical School, Gwangju, Korea

Objectives : This study was performed to investigate the associations between the metabolic syndrome (MetS) and inflammatory markers.

Methods : This cross-sectional analysis was performed using data from 1578 Koreans aged 40-69 years residing in a rural area. We investigated associations between MetS and circulating high sensitivity C-reactive protein (hs-CRP), white blood cells (WBC) and adiponectin. MetS was defined using the criteria proposed by the National Cholesterol Education Program Adult Treatment Panel III (ATP-III).

Results : Increased WBC counts and hs-CRP levels and decreased adiponectin levels were observed in subjects with MetS. WBC, hs-CRP and adiponectin levels linearly deteriorated with an increase in the number of MetS components (all ptrend $<0.005$ ). Finally, adjusted odds ratios (ORs) for the risk of MetS by increase/decrease in 3 inflammatory markers were calculated by multivariate logistic regression analyses. In terms of changes in inflammation markers, in men, the adjusted ORs (95\% confidence interval) were $1.15(1.01-1.31)$ for WBC, 1.64 (1.02-2.64) for hs-CRP, and 0.19 (0.08-0.45) for adiponectin, whereas corresponding adjusted ORs (95\% $\mathrm{Cls}$ ) in women were 1.27 (1.15-1.40), 0.98 (0.67-1.42), 0.09 (0.04-0.18), respectively.

Conclusions : Serum adiponectin levels and WBC counts were found to be strongly associated with MetS in both sexes. However, hs-CRP lost its significance after adjusting for BMI and other inflammatory markers in women. This study shows that inflammatory response is associated with MetS in the Korean population. Further prospective studies are necessary to confirm the contribution made by inflammatory markers to the development of MetS.

\section{J Prev Med Public Health 2008;41(6):413-418}

$\overline{\text { Key words }}$ : Adiponectin, C-reactive protein, Inflammation, Metabolic syndrome, White blood cells

\section{INTRODUCTION}

The metabolic syndrome (MetS) is a cluster of atherosclerotic cardiovascular disease risk factors, namely abdominal adiposity, high blood pressure, elevated triglyceride, low highdensity lipoprotein (HDL) cholesterol and impaired glucose tolerance. Furthermore, the high prevalence of MetS has made it a serious public health problem [1,2]. The high prevalence of MetS is of considerable concern, because several studies have shown people with MetS are more likely to die prematurely and that they are at greater risk of developing diabetes mellitus and cardiovascular disease $[3,4]$.

MetS is believed to be associated with chronic inflammatory response which is characterized by abnormal cytokine production and the activations of inflammatory signaling pathways [5]. Evidence for this belief is provided by observations of associations between high levels of $\mathrm{C}$-reactive protein (CRP), a sensitive marker of subclinical inflammation and insulin resistance or components of MetS [2,6-9].

Recently investigators have reported that increased white blood cell (WBC) count, a biological marker of systemic inflammation, is associated with the components of MetS, and it has been suggested that the mechanism involved is associated with the promotion of the atherothrombotic process by elevated WBC levels [10-12].

An adipocyte-derived plasma protein, adiponectin, has also been considered to be a key molecule in the pathogenesis of MetS [2]. Adiponectin is an adipokine that is abundantly expressed in human adipose tissue and directly sensitizes the body to insulin. Furthermore elevated body fat, obesity, the presences of insulin resistance and type 2 diabetes are characterized by low plasma adiponectin concentrations [13-15]. Thus, adiponectin is currently viewed as an anti-inflammatory adipocytokine.

Accordingly, it appears reductions in antiinflammatory or an increased in proinflammatory markers underlies the development of MetS. However, to our knowledge, few studies have measured proinflammatory and anti-inflammatory markers in a single population of Koreans, and thus relations between inflammatory markers and MetS cannot be evaluated. Therefore, we conducted this cross-sectional study to investigate the independent associations between MetS and these inflammatory markers 
and MetS, and evaluated their magnitude in relation to MetS in Korean adults.

\section{MATERIALS AND METHODS}

\section{Study Subjects}

We studied a population of 1,922 Korean adults (40-69 years old), living in a rural community, in Naju, Jeollanamdo. These subjects had participated in the survey of Korean Rural Genomic Cohort Study (KRGCS, 2006), and have been previously described in detail [16]. Of these 1,922 subjects, 344 subjects that met our exclusion criteria were excluded. In detail, the exclusion criteria were as follows: a self-reported medical history of cardiovascular diseases (CVD), cancer or chronic liver disease $(n=148)$; an elevation of one or more of the following liver enzymes $(n=59)$ : alanine aminotransferase (ALT) twice the upper limit of normal (>85 IU/L) or aspartate aminotransferase (AST) twice the upper limit of normal (>75 IU/L); a highsensitivity CRP (hs-CRP) level of $>10 \mathrm{mg} / \mathrm{L}$ $(n=47)$ or a WBC count above or below the reference range $\left(>10.7\right.$ or $\left.<3.8 \times 10^{3} / \mathrm{uL}\right)$ $(n=145)$, the latter of which implies possible systemic infection. Finally 1,578 people (612 men and 966 women) were eligible for this study. Informed consent was obtained from all subjects prior to their participation in this study, which was approved by the ethical committee.

\section{Data Collection}

Information on socio-demographic factors, lifestyle factors (including alcohol drinking and smoking status), self-reported medical history of CVD or cancer or chronic diseases, and current medication status, and others were obtained by interview. Smoking status was classified as non-smoker, ex-smoker, and current smoker, and alcohol drinking was classified by frequency of drinking alcohol (none, $\leq 1 /$ month, 2-4/month, 2-3/week, $\geq$ $4 /$ week)

Anthropometric measurements, including height, weight and waist and hip circumferences were taken with subjects wearing light clothing by well-trained examiners. Waist circumference was measured to the nearest 0.1 $\mathrm{cm}$ in the horizontal plane at the high point of the iliac crest during minimal respiration. Body mass index (BMI) was calculated as weight in kilograms divided by height in meters squared. Blood pressure was measured with a mercury sphygmomanometer using right arms, in a sitting position, after a 5-min rest. Systolic and diastolic blood pressures were recorded twice and averages were used for the data analysis.

Blood samples were drawn from an antecubital vein after an 8-12 hr overnight fast. Samples were stored at $-70^{\circ} \mathrm{C}$ until required for biochemical assays. Glucose, triglyceride, HDL-cholesterol, total cholesterol, ALT, and AST were measured using enzymatic methods (ADVIA 1650, Bayer, USA). Hs-CRP was analyzed by latex nephelometry. Adiponectin concentrations were determined by ELISA. WBC counts were performed using autoanalyzer.

\section{Definition of MetS}

MetS was defined as described by the National Cholesterol Education Program Adult Treatment Pane III (NCEP-ATP III), except for abdominal obesity by waist circumference [17]. In the present study, we used a modified waist circumference cutoff of $>90 \mathrm{~cm}$ for men and $>85 \mathrm{~cm}$ for women [18]. Therefore, in this study, individuals having three or more of the five following criteria were defined as having MetS: 1) high blood pressure ( $\geq 130 / 85$ $\mathrm{mmHg}$ ) or anti-hypertensive medication, 2) elevated fasting blood glucose ( $\geq 100 \mathrm{mg} / \mathrm{dL}$ ) or anti-diabetic medication, 3) hypertriglyceridemia ( $\geq 150 \mathrm{mg} / \mathrm{dL}$ ), 4) low HDLcholesterol (men, <40 mg/dL; women, <50 $\mathrm{mg} / \mathrm{dL}), 5$ ) abdominal obesity by waist circumference (men, $>90 \mathrm{~cm}$; women, $>85$ $\mathrm{cm})$.

\section{Statistical Analysis}

All statistical analyses were conducted on men and women separately, using the SPSS statistical package for Windows version 12.0 (SPSS Inc, Chicago, IL). All continuous variables are shown as means $\pm \mathrm{SD}$, except for fasting glucose, triglyceride, hs-CRP and adiponectin. To approximate normal distributions, log-transformed values were used in the analysis, and transformed back for data presentation and presented as geometric means and $95 \%$ confidence intervals (CI) for these means.

The student's t-test and the chi-square test were used to compare differences. Under a general linear model (GLM), differences between the levels of inflammatory markers in subjects with different numbers of clustered MetS components were compared by analysis of covariance (ANCOVA) after adjusting for age, smoking status and frequency of alcohol drinking as covariates. To permit direct comparison between inflammatory markers, odds ratios (ORs) and 95\% CI for MetS of a 1SD increase in WBC, log-transformed CRP and adiponectin were calculated with multivariate logistic regression analyses. ORs were evaluated using three models of independent variables in addition to sex, age, smoking status and frequency of alcohol drinking as follows - model 1, each inflammatory marker only; model 2, BMI and each inflammatory marker; model 3, BMI and all markers simultaneously.

\section{RESULTS}

The personal and clinical characteristics of the study subjects are presented in Table 1. The prevalences of MetS in the study population were $35.8 \%$ in men, and $40.0 \%$ in women. Personal characteristics, such as, age, income, educational level, smoking and drinking status, were significantly different between the sexes. Men had higher BMI, WC, systolic blood pressure (SBP), diastolic blood pressure 
(DBP), glucose, WBC and hs-CRP values, but low HDL-cholesterol and adiponectin values.

Tables 2 and 3 show mean values of inflammatory markers according to the presence and absence of each MetS component, and according to the presence and absence of MetS in men and women. In men, significantly higher levels of WBC and hsCRP were observed in those with abdominal obesity and a high triglyceride level. However, significantly lower levels of adiponectin were observed in those with any MetS component than in those without any component of MetS The mean values of WBC, hs-CRP and adiponectin were statistically different between men with and without MetS.

In women, mean values of $\mathrm{WBC}$, hs-CRP and adiponectin were statistically different for subjects with and without a MetS component (except for low HDL-cholesterol) and for those with and without MetS.

In both sexes, as the number of clustered MetS components (ie, 0, 1, 2, 3 and 4+) increased, the adjusted means of WBC and hsCRP increased linearly and adjusted adiponectin levels decreased linearly (Table 4).

Associations between each inflammatory marker and MetS were evaluated by multivariate logistic regression analysis (Table 5). In men, associations between each inflammatory marker and MetS were statistically significant, and after adjusting for all markers and BMI, WBC count, hs-CRP and adiponectin were found to be independently associated with MetS. However, in women, the association between hs-CRP and MetS was not statistically significant after additional adjusting for BMI and all markers.

\section{DISCUSSION}

This study was performed to identify associations between inflammatory markers, namely, WBC, hs-CRP and adiponectin and MetS in an adult Korean population. The results of this study show that the inflammatory

Table 1. Demographic and clinical characteristics of the study subjects by sex

\begin{tabular}{|c|c|c|c|c|}
\hline Variables" & Male & Female & Total & p-value \\
\hline Age, yr & $58.9(7.9)$ & $58.0(7.8)$ & $58.4(7.9)$ & 0.040 \\
\hline \multicolumn{5}{|l|}{ Income, 10,000 won/month } \\
\hline-49 & $194(36.5)$ & $441(57.1)$ & $635(48.7)$ & $<0.001$ \\
\hline $50-99$ & $140(26.4)$ & $185(23.9)$ & $325(24.9)$ & \\
\hline $100-149$ & $126(23.7)$ & $84(10.9)$ & $210(16.1)$ & \\
\hline $150-199$ & $30(5.6)$ & $31(4.0)$ & $61(4.7)$ & \\
\hline $200+$ & $41(7.7)$ & $32(4.1)$ & $73(5.6)$ & \\
\hline \multicolumn{5}{|l|}{ Educational level } \\
\hline Uneducated & $35(5.8)$ & $237(24.7)$ & $272(17.4)$ & $<0.001$ \\
\hline Primary school & $281(46.4)$ & $558(58.2)$ & $839(53.6)$ & \\
\hline Middle school & $153(25.3)$ & $112(11.7)$ & $265(16.9)$ & \\
\hline High school & $113(18.7)$ & $47(4.9)$ & $160(10.2)$ & \\
\hline College+ & $23(3.8)$ & $5(0.5)$ & $28(1.8)$ & \\
\hline Current smokers & $217(35.5)$ & $14(1.4)$ & $231(14.6)$ & $<0.001$ \\
\hline Current drinkers & $397(64.5)$ & $318(33.1)$ & $715(45.6)$ & $<0.001$ \\
\hline Body mass index, $\mathrm{kg} / \mathrm{m}^{2}$ & $23.8(3.0)$ & $24.5(3.3)$ & $24.2(3.2)$ & $<0.001$ \\
\hline Waist circumference, $\mathrm{cm}$ & $86.8(7.5)$ & $83.5(8.0)$ & $84.7(8.0)$ & $<0.001$ \\
\hline Systolic blood pressure, $\mathrm{mmHg}$ & $130.7(17.0)$ & $128.9(19.1)$ & $129.6(18.3)$ & 0.040 \\
\hline Diastolic blood pressure, $\mathrm{mmHg}$ & $82.8(10.6)$ & $80.9(11.1)$ & $81.6(10.9)$ & 0.001 \\
\hline Glucose, $\mathrm{mg} / \mathrm{dL}^{+}$ & $99.0(1.3)$ & $92.8(1.2)$ & $95.2(1.3)$ & $<0.001$ \\
\hline Triglyceride, $\mathrm{mg} / \mathrm{dL}+$ & $140.2(1.7)$ & $133.3(1.7)$ & $135.9(1.7)$ & 0.071 \\
\hline HDL-cholesterol, mg/dL & $44.6(11.4)$ & $46.5(10.0)$ & $45.7(10.6)$ & 0.001 \\
\hline White blood cell, $10^{3} / \mathrm{uL}$ & $7.2(1.5)$ & $6.7(1.5)$ & $6.9(1.5)$ & $<0.001$ \\
\hline $\mathrm{Hs}-\mathrm{CRP}, \mathrm{mg} / \mathrm{L}+$ & $0.9(2.7)$ & $0.7(2.8)$ & $0.76(2.7)$ & $<0.001$ \\
\hline Adiponectin, $\mathrm{ng} / \mathrm{mL}+$ & $6,283.5(1.7)$ & $9,620.6(1.6)$ & $8,158.3(1.7)$ & $<0.001$ \\
\hline Metabolic syndrome & $219(35.8)$ & $386(40.0)$ & $605(38.3)$ & 0.108 \\
\hline
\end{tabular}

*Variable values are expressed as mean (standard deviations, SD) or as numbers (percentages), as applicable.

Geometric means and SDs were given:

Table 2. Relationships between inflammatory markers and MetS components and the presence of MetS in men

\begin{tabular}{|c|c|c|c|c|c|c|c|}
\hline \multirow{2}{*}{ MetS component } & \multirow{2}{*}{$\mathrm{n}$} & \multicolumn{2}{|c|}{$\mathrm{WBC}, 10^{3} / \mathrm{uL}$} & \multicolumn{2}{|c|}{ Hs-CRP, mg/L } & \multicolumn{2}{|c|}{ Adiponectin, ng/mL } \\
\hline & & $\mathrm{M}(\mathrm{SD})^{*}$ & p-value & $\mathrm{M}(\mathrm{SD}){ }^{\dagger}$ & p-value & $\mathrm{M}(\mathrm{SD}) \dagger$ & p-value \\
\hline \multicolumn{8}{|l|}{ Abdominal obesity } \\
\hline Present & 189 & $7.46(1.35)$ & 0.005 & $1.08(2.30)$ & $<0.001$ & $5,692.46(1.65)$ & 0.002 \\
\hline Absent & 423 & $7.11(1.56)$ & & $0.79(2.77)$ & & $6,567.50(1.73)$ & \\
\hline \multicolumn{8}{|l|}{ Low HDL-cholesterol } \\
\hline Present & 224 & $7.28(1.46)$ & 0.421 & $0.89(2.53)$ & 0.773 & $5,557.76(1.71)$ & $<0.001$ \\
\hline Absent & 388 & $7.18(1.53)$ & & $0.86(2.72)$ & & $6,745.28(1.69)$ & \\
\hline \multicolumn{8}{|l|}{ High triglyceride } \\
\hline Present & 267 & $7.47(1.44)$ & $<0.001$ & $0.98(2.38)$ & 0.010 & $5,741.16(1.65)$ & $<0.001$ \\
\hline Absent & 345 & $7.02(1.53)$ & & $0.80(2.83)$ & & 6,739.07 (1.74) & \\
\hline \multicolumn{8}{|l|}{ High glucose } \\
\hline Present & 183 & $7.30(1.53)$ & 0.385 & $1.02(2.53)$ & 0.010 & $5,689.84(1.76)$ & 0.003 \\
\hline Absent & 429 & $7.18(1.50)$ & & $0.82(2.68)$ & & 6,555.41 (1.68) & \\
\hline \multicolumn{8}{|l|}{ Raised blood pressure } \\
\hline Present & 374 & $7.27(1.50)$ & 0.297 & $0.91(2.71)$ & 0.224 & $5,915.62(1.65)$ & 0.001 \\
\hline Absent & 238 & $7.13(1.52)$ & & $0.82(2.61)$ & & $6,908.76(1.78)$ & \\
\hline \multicolumn{8}{|l|}{ Metabolic syndrome } \\
\hline Present & 219 & $7.45(1.43)$ & 0.003 & $1.05(2.36)$ & $<0.001$ & $5,405.05(1.66)$ & $<0.001$ \\
\hline Absent & 393 & $7.08(1.53)$ & & $0.79(2.77)$ & & $6,834.39(1.71)$ & \\
\hline
\end{tabular}

${ }^{\text {*} V a r i a b l e ~ v a l u e s ~ a r e ~ e x p r e s s e d ~ a s ~ m e a n s ~(s t a n d a r d ~ d e v i a t i o n s, ~ S D) . ~ † G e o m e t r i c ~ m e a n s ~ a n d ~ S D s ~ w e r e ~ g i v e n: ~}$

markers WBC and adiponectin are associated with MetS in healthy Korean men and women, but that hs-CRP is associated with MetS in men only.

In this study, WBC count was not found to be significantly associated with low HDLcholesterol in either sex, or with high glucose and a raised blood pressure in men. However, an increased WBC count was found to be associated with MetS component number and with the presence of MetS, even after adjusting for other inflammatory markers and related risk factors. This result supports the findings of previous studies concerning a linear independent association between WBC count and the risk of MetS [10-12,19,20]. As an increased WBC count may exacerbate insulin resistance and lead to MetS. In fact, the potential candidate factors that increase WBC count and exacerbate insulin resistance include pro- 
Table 3. Relationships between inflammatory markers and MetS components and the presence of MetS in women

\begin{tabular}{|c|c|c|c|c|c|c|c|}
\hline \multirow{2}{*}{ MetS component } & \multirow{2}{*}{$\mathrm{n}$} & \multicolumn{2}{|c|}{$\mathrm{WBC}, 10^{3} / \mathrm{uL}$} & \multicolumn{2}{|c|}{ Hs-CRP, mg/L } & \multicolumn{2}{|c|}{ Adiponectin, $\mathrm{ng} / \mathrm{mL}$} \\
\hline & & $\mathrm{M}(\mathrm{SD})^{*}$ & $\mathrm{p}$-value & $\mathrm{M}(\mathrm{SD})^{\mathrm{a}}$ & $\mathrm{p}$-value & $\mathrm{M}(\mathrm{SD})^{\mathrm{a}}$ & $\mathrm{p}$-value \\
\hline \multicolumn{8}{|l|}{ Abdominal obesity } \\
\hline Present & 405 & $6.82(1.56)$ & 0.004 & $0.90(2.61)$ & $<0.001$ & $8,647.7(1.62)$ & $<0.001$ \\
\hline Absent & 560 & $6.54(1.50)$ & & $0.57(2.61)$ & & $10,392.0(1.59)$ & \\
\hline \multicolumn{8}{|l|}{ Low HDL-cholesterol } \\
\hline Present & 638 & $6.70(1.54)$ & 0.188 & $0.72(2.72)$ & 0.149 & $9,086.6(1.63)$ & $<0.001$ \\
\hline Absent & 327 & $6.57(1.50)$ & & $0.65(2.80)$ & & $10,754.7(1.55)$ & \\
\hline \multicolumn{8}{|l|}{ High triglyceride } \\
\hline Present & 389 & $7.03(1.49)$ & $<0.001$ & $0.79(2.65)$ & 0.001 & $8,525.1(1.62)$ & $<0.001$ \\
\hline Absent & 576 & $6.41(1.51)$ & & $0.64(2.79)$ & & $10,440.0(1.58)$ & \\
\hline \multicolumn{8}{|l|}{ High glucose } \\
\hline Present & 186 & $7.18(1.49)$ & $<0.001$ & $0.96(2.46)$ & $<0.001$ & $8,167.7(1.66)$ & $<0.001$ \\
\hline Absent & 779 & $6.53(1.52)$ & & $0.64(2.78)$ & & $10,004.6(1.59)$ & \\
\hline \multicolumn{8}{|l|}{ Raised blood pressure } \\
\hline Present & 511 & $6.84(1.57)$ & $<0.001$ & $0.80(2.72)$ & $<0.001$ & 9,153.8 (1.63) & 0.001 \\
\hline Absent & 454 & $6.45(1.46)$ & & $0.59(2.71)$ & & $10,174.2(1.60)$ & \\
\hline \multicolumn{8}{|l|}{ Metabolic syndrome } \\
\hline Present & 386 & $7.01(1.49)$ & $<0.001$ & $0.87(2.58)$ & $<0.001$ & $8,333.0(1.64)$ & $<0.001$ \\
\hline Absent & 579 & $6.42(1.49)$ & & $0.60(2.79)$ & & $10,587.7(1.56)$ & \\
\hline
\end{tabular}

*Variable values are expressed as means (standard deviations, SD). a Geometric means and SDs were given:

Table 4. Adjusted means (95\% confidence interval) of WBC, hs-CRP and adiponectin with increasing number of MetS components by sex - after adjusting for age, smoking status, and frequency of drinking alcohol

\begin{tabular}{cccc}
\hline No. of MetS components & WBC, $10^{3} / \mathrm{uL}$ & hs-CRP, mg/L & Adiponectin, $\mathrm{ng} / \mathrm{mL}$ \\
\hline Men & & & \\
$0 \quad(\mathrm{n}=79)$ & $6.89(6.57-7.21)$ & $0.79(0.64-0.97)$ & $7,691.6(7,112-1-8,933.1)$ \\
$1(\mathrm{n}=145)$ & $7.04(6.80-7.27)$ & $0.71(0.61-0.83)$ & $7,311.4(6,714.3-7,961.6)$ \\
$2(\mathrm{n}=168)$ & $7.16(6.94-7.38)$ & $0.84(0.73-0.97)$ & $6,039.5(5,711.9-6,531.3)$ \\
$3(\mathrm{n}=131)$ & $7.37(7.12-7.62)$ & $1.03(0.87-1.21)$ & $5,597.6(5,116.8-6,109.4)$ \\
$4+(\mathrm{n}=87)$ & $7.67(7.36-7.97)$ & $1.13(0.93-1.38)$ & $5,116.8(4,581.4-5,701.6)$ \\
p-trend & 0.003 & 0.001 & $<0.001$ \\
Women & & & \\
$0(\mathrm{n}=89)$ & $6.19(5.87-6.50)$ & $0.43(0.35-0.53)$ & $12,560.3(11,428.8-13,803.8)$ \\
$1(\mathrm{n}=222)$ & $6.33(6.13-6.53)$ & $0.57(0.50-0.65)$ & $11,428.8(10,789.5-12,133.9)$ \\
$2(\mathrm{n}=269)$ & $6.57(6.39-6.75)$ & $0.72(0.64-0.81)$ & $9,682.8(9,183.3-10,232.9)$ \\
$3(\mathrm{n}=212)$ & $6.77(6.57-6.98)$ & $0.78(0.68-0.89)$ & $8,749.8(8,222.4-9,289.7)$ \\
$4+(\mathrm{n}=174)$ & $7.30(7.07-7.52)$ & $0.92(0.80-1.07)$ & $7,481.7(6,998.4-7,998.3)$ \\
p-trend & $<0.001$ & $<0.001$ & $<0.001$ \\
\hline
\end{tabular}

Table 5. Adjusted* ORs $\left(95 \% \mathrm{Cl}\right.$ ) of MetS according to $1-\mathrm{SD}^{+}$increase in WBC counts, and logtransformed hs-CRP and log-transformed adiponectin values

\begin{tabular}{cccc}
\hline \multicolumn{1}{c}{ Variables } & Model ${ }^{\ddagger}$ & Model 2 ${ }^{\ddagger}$ & Model 3 ${ }^{\ddagger}$ \\
\hline Men & & & \\
WBC, $10^{3} / \mathrm{uL}$ & $1.36(1.14-1.61)$ & $1.26(1.03-1.53)$ & $1.23(1.00-1.50)$ \\
hs-CRP, $\mathrm{mg} / \mathrm{L}$ & $1.41(1.19-1.69)$ & $1.31(1.08-1.59)$ & $1.23(1.01-1.51)$ \\
Adiponectin, $\mathrm{ng} / \mathrm{mL}$ & $0.63(0.52-0.75)$ & $0.66(0.55-0.81)$ & $0.68(0.56-0.83)$ \\
Women & & & \\
WBC, $10^{3} / \mathrm{uL}$ & $1.48(1.29-1.69)$ & $1.42(1.22-1.64)$ & $1.44(1.23-1.68)$ \\
hs-CRP, $\mathrm{mg} / \mathrm{L}$ & $1.39(1.21-1.59)$ & $1.16(0.99-1.35)$ & $0.99(0.84-1.17)$ \\
Adiponectin, $\mathrm{ng} / \mathrm{mL}$ & $0.54(0.47-0.63)$ & $0.61(0.52-0.71)$ & $0.60(0.51-0.70)$ \\
\hline
\end{tabular}

*Adjusted for age, smoking status and frequency of drinking alcohol.

In men, SD for WBC=1.51, SD for $\log ($ hs-CRP) $=0.42$, SD for $\log$ (adiponectin) $=0.23$; In women, SD for WBC=1.53, SD for $\log ($ hs-CRP $)=0.44, \mathrm{SD}$ for $\log$ (adiponectin) $=0.21$

Independent variables were set as follows : model 1, each marker only; model 2, each marker and BMI; model 3, all markers and BMI.

inflammatory cytokines and adipocytokines [21].

Hs-CRP is a sensitive marker of systemic inflammation, and is produced by the liver. Various epidemiological studies have reported a linear association between hs-CRP levels and found to be strongly and positively associated with hs-CRP.

However, we did not observe an independent association between hs-CRP and MetS in the whole study population. In men, hs-CRP was found to be significantly increase the risk of MetS after adjusting for age, smoking status, drinking frequency, BMI and other inflammatory markers including WBC and adiponectin, but in women, hs-CRP was not found to be associated with MetS after adjusting for other covariates. To date the influence of sex on the association between inflammation and MetS has not been determined. Although in this study, several general factors were found to differ between men and women, and it is likely that another set of factors related to inflammation impact this situation, such as, cyclical hormonal changes associated with the menstrual cycle and subclinical autoimmune reactions [23]. Overall, available data on the effects of gender relationships between hs-CRP and MetS or atherosclerosis is reported [24,25].

Adiponectin, an anti-inflammatory and antiatherogenic adipocytokine was found to be more strongly associated with MetS than the other pro-inflammatory markers studies which concurs with the findings of previous studies performed in various population $[2,7,9,26]$ and suggests that a reduced level of protection against inflammation is more potently associated with the development of MetS than increases in the levels of pro-inflammatory proteins.

Adiponectin, is secreted predominantly by adipocytes [27], and has been related to obesity, adipose tissue distribution, dyslipidemia, hypertension, and insulin resistance, all of which are related to clustering of the components of MetS [26]. In a recent in vitro study, adiponectin was found to increase IL-10 mRNA expression in human macrophages and to inhibit vascular inflammation - possibly by lowering hs-CRP and TNF- $\alpha$ levels [28]. Pleiotropic functions of adiponectin on lipid 
and glucose metabolism and NO synthesis may also contribute to the strong association between adiponectin and MetS [2,29]. The results of this study thus raise the possibility that adiponectin is a key player in the development of MetS and that it may be marker of the MetS. Further prospective studies are required to confirm the contribution of adiponectin to the development of MetS. If this were confirmed, it would have substantial implications for the prevention and management of MetS and atherosclerotic diseases, as these involve the suppression of inflammatory conditions [30] rather than incitement of anti-inflammatory conditions [2]. Some limitations of this study must be considered. First, this study had a crosssectional design, which prevents us from drawing inferences concerning the directionality of associations. Second, the study population was composed of individuals who living in a rural area that underwent a voluntarily health examination. Thus, the study population might have been substantially different in some respects from the general Korea population.

Nevertheless, our results show that in many people MetS is associated with inflammatory response in the subclinical or normal range. In conclusion, inflammatory markers, such as WBC and adiponectin, were associated with MetS in some Korean. The present results suggest that inflammation is substantial key mechanism in the development of MetS.

\section{REFERENCES}

1. Ford ES, Giles WH, Dietz WH. Prevalence of the metabolic syndrome among US adults: Findings from the third National Health and Nutrition Examination Survey. JAMA 2002; 287(3): 356-359.

2. Matsushita K, Yatsuya H, Tamakoshi K, Wada K, Otsuka R, Takefuji E, et al. Comparison of circulating adiponectin and proinflammatory markers regarding their association with metabolic syndrome in Japanese men. Arterioscler Thromb Vasc Biol 2006; 26(4): 871-876.
3. Isomaa B, Almgren P, Tuomi T, Forsen B, Lahti $\mathrm{K}$, Nissen M, et al. Cardiovascular morbidity and mortality associated with the metabolic syndrome. Diabetes Care 2001; 24(4): 683-689.

4. Risk Factor and Life Expectancy Research Group, Trevisan M, Liu J, Bahsas FB, Menotti A. Syndrome $\mathrm{X}$ and mortality: A populationbased study. Am J Epidemiol 1998; 148(10); 958-966.

5. Wellen KE, Hotamisligil GS. Obesity-induced inflammatory changes in adipose tissue. $\mathrm{J} \mathrm{Clin}$ Invest 2003; 112(12): 1785-1788

6. Gonzaalez AS, Guerrero DB, Soto MB, Diaz SP, Martinez-Olmos A, Vidal O. Metabolic syndrome, insulin resistance and the inflammation markers C-reactive protein and ferritin. Eur J Clin Nutr 2006; 60(6): 802-809.

7. Lim S, Lee HK, Kimm KC, Park C, Shin C, Cho NH. C-reactive protein level as an independent risk factor of metabolic syndrome in the Korean population. Diabetes Res Clin Pract 2005; 70(2): 126-133.

8. Kerner A, Avizohar O, Sella R, Bartha P, Zinder $\mathrm{O}$, Markiewicz W, et al. Association between elevated liver enzymes and $\mathrm{C}$-reactive protein: Possible hepatic contribution to systemic inflammation in the metabolic syndrome. Arterioscler Thromb Vasc Biol 2005; 25(1): 193-197.

9. Choi KM, Ryu OH, Lee KW, Kim HY, Seo JA, Kim SG, et al. Serum adiponectin, interleukin10 levels and inflammatory markers in the metabolic syndrome. Diabetes Res Clin Pract 2007; 75(2): 235-240.

10. Targher G, Siedell JC, Tonoli M, Muggeo M, De Sandre G, Cigolini M. The white blood cell count: Its relationship to plasma insulin and other cardiovascular risk factors in healthy male individuals. J Intern Med 1996; 239(5): 435-441.

11. Ford ES. The metabolic syndrome and Creactive protein, fibrinogen, and leukocyte count : Findings from the Third National Health and Nutrition Examination Survey. Atherosclerosis 2003; 168(2): 351-358.

12. Desai MY, Dalal D, Santos RD, Carvalho JA, Nasir K, Blumenthal RS. Association of body mass index, metabolic syndrome, and leukocyte count. Am J Cardiol 2006; 97(6): 835-838.

13. Weyer C, Funahashi T, Tanaka S, Hotta K, Matsuzawa Y, Prateley RE, et al. Hypoadiponectinemia in obesity and type 2 diabetes: Close association with insulin resistance and hyperinsulinemia. J Clin Endocrinol Metab 2001; 86(5): 1930-1935.

14. Choi KM, Lee J, Lee KW, Seo JA, Oh JH, Kim SG, et al. Serum adiponectin concent- rations predict the development of type 2 diabetes and the metabolic syndrome in elderly Koreans. Clin Endocrinol 2004; 61(1): 75-80.

15. Matsuzawa Y, Funahashi T, Kihara S, Shimomura I. Adiponectin and metabolic syndrome. Arterioscler Thromb Vasc Biol 2004; 24(1): 29-33.

16. Ryu SY, Kim KS, Park J, Kang MG, Han MA. Serum ferritin and risk of the metabolic syndrome in some Korean rural residents. $J$ Prev Med Public Health 2008; 41(2): 115-120. (Korean)

17. Grundy SM, Brewer HB Jr, Cleeman JI, Smith SC Jr, Lenfant C, American Heart Association, et al. Definition fo metabolic syndrome: Report of the National Heart, Lung, and Blood Institute/American Heart Association conference on scientific issues related to definition. Circulation 2004; 109(3): 433-438.

18. Lee SY, Parak HS, Kim DJ, Han JH, Kim SM, Cho GJ, et al. Appropriate waist circumference cutoff points for central obesity in Korean adults. Diabetes Res Clin Pract 2007; 75(1): 72-80.

19. Nakanishi N, Sato M, Shirai K, Nakajima K, Murakami S, Takatoeige T, et al. Associations between white blood cell count and features of the metabolic syndrome in Japanese male office workers. Ind Health 2002; 40(3):273277.

20. Lohsoonthorn V, Dhanamun B, Williams M. Prevalence of metabolic syndrome and its relationship to white blood cell count in a population of Thai men and women receiving routine health examinations. Am J Hypertens 2006; 19(4): 339-45.

21. Ishizaka N, Ishizaka Y, Toda EI, Nagai R, Koike K, Hashimoto H, et al. Relationship between smoking, white blood cell count and metabolic syndrome in Japanese women. Diabetes Res Clin Pract 2007; 78(1):72-76.

22. Festa A, D' Agostino R Jr, Howard G, Mykkanen L, Tracy RP, Haffner SM. Chronic subclinical inflammation as part of the insulin resistance syndrome: The Insulin Resistance Atherosclerosis Study (IRAS). Circulation 2000; 102(1): 42-47.

23. Makita S, Nakamura M, Horamori K. The association of C-reactive protein levels with carotid intima-media complex thickness and plaque formation in the general population. Stroke 2005; 36(10): 2138-2142.

24. Blackburn R, Giral P, Bruckert E, Andre JM, Gonbert S, Bernard M, et al. Elevated Creactive protein constitutes an independent predictor of advanced carotid plaques in dyslipidemic subjects. Arterioscler Thromb Vasc Biol 2001; 21(12): 1962-1968. 
25. Wang TJ, Nam BH, Wilson PW, Wolf PA, Levy D, Polak JF, et al. Association of Creactive protein with caritid atherosclerosis in men and women: The Framingham Heart Study. Arterioscler Thromb Vasc Biol 2002; 22(10): 1662-1667.

26. Matsuzawa Y, Funahashi T, Kihara S, Shimomura I. Adiponectin and metabolic syndrome. Arterioscler Thromb Vasc Biol 2004; 24(1): 29-33.

27. Salas-Salvado J, Granada M, Bullo M,
Corominas A, Casas P, Foz M. Plasma adiponectin distribution in a Mediterranean population and its association with cardiovascular risk factors and metabolic syndrome. Metabolism 2007; 56(11): 14861492.

28. Kumada M, Kihara S, Ouchi N, Kobayashi H, Okamoto Y, Ohashi K, et al. Adiponectin specifically increased tissue inhibitor of metalloproteinase-1 through interleukin-10 expression in human macrophages. Circulation
2004; 109(17): 2046-2049.

29. Chen $\mathrm{H}$, Montagnani M, Funahashi T, Shimomura I, Quon MJ. Adiponectin stimulates production of nitric oxide in vascular endothelial cells. J Biol Chem 2003; 278(45): 45021-45026.

30. Torres JL, Ridker PM. Clinical use of high sensitivity C-reactive protein for the prediction of adverse cardiovascular events. Curr Opin Cardiol 2003; 18(6): 471-478. 